\title{
A importância do brincar no processo de inclusão de alunos/as especiais no ambiente educacional
}

The importance of playing in the process of including special students in the educational environment

La importancia de jugar en el proceso de inclusión de alumnos especiales en el entorno educativo

Recebido: 31/08/2021 | Revisado: 02/09/2021 | Aceito: 02/09/2021 | Publicado: 03/09/2021

Fernando Icaro Jorge Cunha

ORCID: https://orcid.org/0000-0002-0064-4039

Universidade Federal do Pampa, Brasil E-mail: icaro729@gmail.com

Maria José Baltar de Azambuja ORCID: https://orcid.org/0000-0002-0897-7380 Rede Municipal de Ensino de Porto Alegre, Brasil E-mail: mj.azambuja@bol.com.br

Adriana da Silva Biavaschi

ORCID: https://orcid.org/0000-0003-3521-4378 Universidade Federal do Pampa, Brasil

E-mail: fereadri2002@gmail.com

Márcio da Mota Machado Filho

ORCID: https://orcid.org/0000-0002-3443-2931 Universidade Federal de Santa Maria, Brasil

E-mail: marciotm95@gmail.com

Marlise Grecco de Souza Silveira ORCID: https://orcid.org/0000-0003-4612-9128 $10^{\mathrm{a}}$ Coordenadoria Regional de Educação, Brasil

E-mail: marlisegreccos@gmail.com

Luciana Martins Vieira

ORCID: https://orcid.org/0000-0003-3104-3583 Rede Municipal de Ensino de Porto Alegre, Brasil

E-mail: lumartinsv@gmail.com

Janete Mendonça Chrispim Maia

ORCID: https://orcid.org/0000-0002-6338-2267

Rede Municipal de Ensino de Nova Iguaçu, Brasil

E-mail: jmendonca.prof@gmail.com

\begin{abstract}
Resumo
Atividades lúdicas incorporadas ao processo de ensino-aprendizagem da Educação Especial, podem potencializar significativamente a construção de conhecimentos e o desenvolvimento cognitivo, social e emocional de crianças especiais. Nesse sentido, este estudo tem por objetivo apresentar a visão de diferentes autores e docentes de uma escola especial do município de Porto Alegre, a respeito da importância do brincar no processo de inclusão de alunos/as especiais no ambiente educacional. Por meio de uma abordagem qualitativa, primeiramente procurou-se discorrer a respeito das atividades lúdicas como fundamentais na formação e socialização das crianças que fazem parte da Educação Especial. No decorrer do trabalho são apresentados alguns estudos bibliográficos sobre o prazer de aprender por meio de jogos e brincadeiras, tornando o ambiente educacional mais significativo e prazeroso, facilitador da aprendizagem, do desenvolvimento pessoal, social e cultural, e da saúde mental dos/as educandos/as da Educação Especial. Assim, ressalta-se que as atividades lúdicas devem ser valorizadas e divulgadas em todas as escolas como instrumento facilitador e construtor de conhecimentos dentro do processo de inclusão de alunos/as especiais.
\end{abstract}

Palavras-chave: Educação especial; Ludicidade; Aprendizagem.

\begin{abstract}
Playful activities incorporated into the teaching-learning process of Special education can significantly enhance the construction of knowledge and the cognitive, social and emotional development of special children. In this sense, this study aims to present the view of different authors and teachers from a special school in the city of Porto Alegre, regarding the importance of playing in the process of inclusion of special students in the educational environment. Through a qualitative approach, we first tried to talk about playful activities as fundamental in the formation and socialization of children who are part of Special education. During the work, some bibliographic studies are presented on the pleasure of learning through games and games, making the educational environment more meaningful and
\end{abstract}


pleasurable, facilitating learning, personal, social and cultural development, and the mental health of students /as of Special education. Thus, it is emphasized that recreational activities should be valued and disseminated in all schools as a facilitator and knowledge building tool within the process of inclusion of special students.

Keywords: Special education; Playfulness; Learning.

\section{Resumen}

Las actividades lúdicas incorporadas al proceso de enseñanza-aprendizaje de la Educación especial pueden mejorar significativamente la construcción de conocimientos y el desarrollo cognitivo, social y emocional de niños especiales. En este sentido, este estudio tiene como objetivo presentar la visión de diferentes autores y docentes de una escuela especial de la ciudad de Porto Alegre, sobre la importancia del juego en el proceso de inclusión de estudiantes especiales en el ámbito educativo. A través de un enfoque cualitativo, primero intentamos hablar de las actividades lúdicas como fundamentales en la formación y socialización de los niños que forman parte de la Educación especial. Durante el trabajo, se presentan algunos estudios bibliográficos sobre el placer de aprender a través de juegos y juegos, haciendo más significativo y placentero el entorno educativo, facilitando el aprendizaje, el desarrollo personal, social y cultural, y la salud mental de los alumnos / as de Educación especial. Así, se enfatiza que las actividades recreativas deben ser valoradas y difundidas en todas las escuelas como facilitadora y herramienta de construcción de conocimiento dentro del proceso de inclusión de estudiantes especiales.

Palabras clave: Educación especial; Alegría; Aprendiendo.

\section{Introdução}

O brincar no ambiente educacional é de suma importância para o desenvolvimento dos/as alunos/as com necessidades educativas especiais, pois ser inserido/a junto à educação, favorece o desempenho cognitivo, social e emocional do/a estudante.

As crianças consideram a brincadeira como uma atividade prazerosa, parte da fase infantil, e pode ser empregada como uma ferramenta que proporciona não apenas aprendizado, mas também inclusão. Assim como as crianças precisam de uma casa, de comida e de carinho, também precisam do ato de brincar, que é inerente à esta etapa da vida infantil. Através de atividades lúdicas é possível aprender e construir situações essenciais para uma vida mais independente, pois estimula a criação de conexões entre o mundo real e o imaginário, promovendo a tomada de decisões e o convívio harmônico com o outro (Dias, 2015).

Brincando, a criança lida com a construção e desconstrução do pensamento infantil, com a linguagem simbólica e as regras associadas ao pensamento lúdico.

Ensinar por meio do Lúdico é promover um brincar diferenciado, é buscar novas maneiras de construir o conhecimento, é uma ferramenta a mais que o/a educador/a poderá utilizar para desenvolver a aprendizagem dos/as alunos/as. "Segundo a perspectiva inclusiva, aceitar as diferenças implica respeitar características, interesses, motivações e os projetos de vida de cada criança, o que só é possível criando estratégias e recursos” (Silva, 2020, p.1).

Ao praticar o ato de brincar, as crianças não veem as limitações umas das outras, elas se percebem como sujeitos, pois ao brincar as crianças não visam a diferença e sim a diversão e a socialização, assim, a ludicidade se apresenta como uma atividade facilitadora no processo de inclusão, pelos valores e fruições que ela proporciona. Para Soares (2010), a brincadeira e/ou o jogo são ações sociais e culturais do ser humano, pois as crianças interagem, compartilham e cooperam umas com as outras, logo, o processo de inclusão ocorre de forma natural.

Nessa perspectiva, Brougère (1997) nos diz que às vezes, o ato de brincar pode ser uma escola de conformismo social, de adaptação a um cenário proposto, sendo que, da mesma maneira, pode tornar-se um universo de criações, de curiosidades e de experiências múltiplas, desde que a sociedade ofereça os meios para a criança. "Acontece que essa abertura marca um dos aspectos essenciais das sociedades modernas, caracterizadas pela indeterminação do futuro de cada indivíduo. A eventualidade da brincadeira corresponde, intimamente, à imprevisibilidade de um futuro aberto" (Brougère, 1997, p. 107).

A criança nunca termina uma brincadeira ou jogo da mesma forma que iniciou, pois enquanto brinca, ela aprende com os demais, conhecimentos valorosos, que dominará e possivelmente carregará para o resto da vida. Ela aprende a lidar com contratempos, aprende regras, aprende que na vida nem sempre ganhamos, enfim, aprende a relacionar-se. "É importante que o 
professor tenha conviç̧ão da importância da atividade de brincar, pois o sucesso das intervenções está voltado para aquilo que ele acredita, desde o preparo dos espaços quanto dos objetos ou brinquedos" (Dias, 2015, p. 22).

Assim, este artigo tem o propósito de apresentar o olhar de diferentes autores e docentes de uma escola especial do município de Porto Alegre, acerca da importância do brincar no processo de inclusão de alunos/as especiais no ambiente educativo.

No decorrer do estudo serão apresentados os procedimentos metodológicos, as leis que tratam sobre o ensino de alunos/as com necessidades educativas especiais, o contexto histórico do lúdico, a concepção do brincar, o lúdico nos processos de aprendizagem e desenvolvimento, o brincar na educação especial e as considerações finais.

\section{Metodologia}

O percurso metodológico desta pesquisa teve uma abordagem qualitativa, caracterizada nas vivências e práticas lúdicas vivenciadas com alunos/as da Educação Especial, bem como pelo desenvolvimento de um estudo bibliográfico acerca de diferentes referenciais teóricos. Para Minayo (2002, p. 21), a pesquisa qualitativa "trabalha com o universo de significados, motivos, aspirações, crenças, valores e atitudes, o que corresponde a um espaço mais profundo das relações, dos processos e dos fenômenos que não podem ser reduzidos à operacionalização de variáveis".

Nesse sentido, Gil (2002, p. 45) salienta que:

[...] a pesquisa bibliográfica é desenvolvida com base em material já elaborado, constituído principalmente de livros e artigos científicos. Embora em quase todos os estudos seja exigido algum tipo de trabalho dessa natureza, há pesquisas desenvolvidas exclusivamente a partir de fontes bibliográficas. Boa parte dos estudos exploratórios pode ser definida como pesquisas bibliográficas. As pesquisas sobre ideologias, bem como aquelas que se propõem a uma análise das diversas posições acerca de um problema, também costumam ser desenvolvidas quase exclusivamente mediante fontes bibliográficas. (Gil, 2002, p. 44).

Para a fundamentação do estudo teórico, recorreu-se a autores como: Almeida (2014), Barnard \& Erickison (1996), Brougère (1997), Ferreira (2007), Huizinga (2001), Rosa (2002), Santos (2011), Vygotsky (1994), Zopelari (2010), dentre outros que tratam sobre a temática pesquisada.

Nessa perspectiva, com o presente artigo buscou-se contemplar estudos bibliográficos sobre o prazer de aprender por meio de jogos e brincadeiras, capazes de tornar o ambiente educacional mais significativo e prazeroso, facilitador da aprendizagem, do desenvolvimento pessoal, social e cultural, e da saúde mental dos/as educandos/as da Educação Especial.

\section{A Legislação Federal Brasileira e a Educação de Alunos/as Especiais}

A legislação que trata da Educação Especial data de 1988, quando foi promulgada a Constituição, ainda vigente, denominada "Constituição Cidadã", porque garantiu direitos a grupos sociais até então marginalizados, como as pessoas com deficiências.

O artigo 205 da Constituição Federal, define a educação como um direito de todos, garantindo o exercício da cidadania e a qualificação para o trabalho e a igualdade de condições de acesso e permanência na escola como um princípio (Brasil, 1988). Em 1994, a portaria do Ministério da Educação e Cultura - MEC, recomenda "a inclusão de conteúdos relativos a aspectos éticos, políticos e educacionais da normalização e integração da pessoa portadora de necessidades especiais nos currículos de formação de docentes" (Gil, 2017, p. 6).

A partir da Declaração de Salamanca em 1944, o Brasil, a exemplo dos demais signatários, começou a implantar políticas de inclusão no ensino regular de alunos com necessidades especiais, essas políticas baseavam-se em um ideal de 
democracia, cujo principal objetivo era a efetiva ampliação de oportunidades para essa população marginalizada (Unesco, 1994).

A Lei de Diretrizes e Bases da Educação Nacional - LDB, no 9.394/96, no Capítulo III, art. 4º, inciso III, diz que é dever do Estado garantir o "atendimento educacional especializado gratuito aos educandos com necessidades especiais, preferencialmente na rede regular de ensino" (Brasil, 1996).

Em 1999 o Decreto n 3.298, dispõe sobre a Política Nacional para a Integração da Pessoa Portadora de Deficiência. A Educação Especial é definida como uma modalidade transversal a todos os níveis e modalidades de ensino.

No ano de 2001 a Resolução CNE/CEB, determina no artigo $2^{\circ}$ que: "Os sistemas de ensino devem matricular todos os alunos, cabendo às escolas organizar-se para o atendimento aos educandos com necessidades educacionais especiais, assegurando as condições necessárias para uma educação de qualidade para todos” (Brasil, 2001).

O Decreto $\mathrm{n}^{\circ} 7.611$ de 2011, dispõe sobre o Atendimento Educacional Especializado - AEE, além de outras providências. Em 2015 foi criada a Lei no 146, Lei Brasileira de Inclusão da Pessoa com Deficiência - LBI, e em 2016 a Lei no 409, que trata da reserva de vagas para pessoas com deficiência nos cursos técnico de nível médio e superior das instituições federais de ensino (Gil, 2017, p. 8).

Atualmente, o Ministério da Educação - MEC está revisando a atual Política Nacional de Educação Especial na Perspectiva da Educação Inclusiva - PNEEPEI, que é de 2008. O texto enfrenta oposição de grupos de educadores, para quem a nova redação seria um retrocesso voltando a estimular a separação das pessoas com deficiência, promovendo a separação dos alunos com e sem deficiência.

\section{Contextos Históricos do Lúdico}

A palavra, lúdico, se origina do latim ludus, que significa brincar. O lúdico é a brincadeira, é o jogo, é a diversão.

Em cada época conforme o contexto histórico e o pensamento dos povos, o lúdico sempre foi algo natural, vivido por todos/as e utilizado como um instrumento de caráter educativo para o desenvolvimento do sujeito. Segundo Roloff, (2010, p. 2) "O lúdico pode trazer à aula um momento de felicidade, seja qual for a etapa de nossas vidas, acrescentando leveza à rotina escolar e fazendo com que o aluno registre melhor os ensinamentos que the chegam, de forma mais significativa".

Para cada época e sociedade a concepção sobre educação sempre teve um entendimento diferenciado, logo o uso do lúdico seguiu tal concepção.

Platão em meados de 367 a.c. afirmava que meninos e meninas nos primeiros anos de vida deveriam realizar juntos as atividades educativas através de jogos, assim como Rabelais, no século XV, proclamava que os ensinamentos deveriam ser por meio do lúdico (Sant'Anna \& Nascimento, 2011).

$\mathrm{Na}$ Grécia antiga, era através dos jogos que se passava ensinamento às crianças. Os índios ensinavam e ensinam seus costumes através da ludicidade. Segundo Sant'Anna \& Nascimento, (2011, p. 22) "No Brasil da Idade Média, os jesuítas ensinavam utilizando brincadeiras como instrumentos para a aprendizagem".

No século XVII e XVIII os artesões começaram a fabricação de brinquedos para divertimento das crianças, no final do século XIX, devido à demanda, os brinquedos começaram a ser fabricados em série, aumentando sua aquisição.

Com a expulsão dos jesuítas em meados de 1758, o uso de jogos para ensino começou a se destacar, porém o Brasil não possuía um sistema de ensino organizado o que prejudicou a prática educativa por meio da ludicidade (Sant'Anna \& Nascimento, 2011).

Nas últimas décadas do século XX, os brinquedos e jogos começaram a ser vistos como meios de aprendizagem em todas as áreas de ensino. 
A utilização do lúdico na educação tem também, além do objetivo de desenvolver o aprendizado de forma mais atrativa para o aluno, o objetivo do resgate histórico-cultural dessas atividades. É um ótimo momento para o reconhecimento do seu histórico familiar e de sua cultura regional. Adquirimos desde criança as mais diferentes formas de conhecimento: seja popular, cientifico, cultural, religioso, aprendendo-as de maneiras e objetivos diferentes, mas com algo comum para todos os seres: o mundo da criança, independente de suas origens, é lúdico e ilusório e o mundo do adulto se abstém de ludicidade, sendo realista. (Sant'Anna \& Nascimento, 2011, p. 22).

Adentrando o século XXI, inserido na sociedade pós-industrial, caracterizada pela produção de serviços, informática, estética, símbolos e valores, o predomínio da globalização, foi criado um modelo de brincar, baseado no tempo livre, na flexibilidade, na criatividade, na individuação e emotividade conjugada com a racionalidade (Zopelari, 2010, p. 4).

\subsection{O lúdico na pré-história}

A era pré-histórica é o período compreendido entre o aparecimento dos primeiros homens, há mais ou menos um milhão de anos e os primeiros registros escritos, datam de aproximadamente 4.000 a.C.

Estudos realizados sobre os homens primitivos dos desenhos e pinturas deixados por eles nas paredes das cavernas, comprovam que o ser primitivo já brincava.

Segundo Huizinga (2001, p. 7), "nas sociedades primitivas as atividades que buscavam satisfazer as necessidades vitais, as atividades de sobrevivência, como a caça, assumiam muitas vezes a forma lúdica". No entanto, muito antes do surgimento da humanidade, já existia o brincar no mundo dos animais.

Os animais não esperaram que os homens os iniciassem na atividade lúdica. É-nos possível afirmar com segurança que a civilização humana não acrescentou características essenciais a ideia geral de jogo. Os animais brincam tal como os homens. Bastará que observemos os cachorrinhos para constatar que, em suas alegres evoluções encontramse presentes todos os elementos essenciais do jogo humano. Convidam-se uns aos outros para brincar mediante um certo ritual de atitudes e gestos. Respeitam a regra que os proíbe morderem, ou pelo menos com violência, a orelha do próximo. Fingem ficar zangados e, o que é mais importante, eles, em tudo isto, experimentam evidentemente imenso prazer e divertimento. Essas brincadeiras dos cachorrinhos constituem apenas uma das formas mais simples de jogo entre os animais. Existem outras formas muito mais complexas, verdadeiras competições, belas representações destinadas a um público. (Huizinga, 2001, p. 18).

De acordo com diversos estudiosos, o jogo e o brincar não são invenções humanas, apesar do homem ter dado significados ao ato de brincar. Estudos que se tem sobre os nossos antepassados, afirmam que as primeiras criaturas que habitavam a terra pertenciam à família hominídea, mais conhecida como australopitecos. Estes foram sofrendo modificações físicas ao longo dos tempos chegando a uma nova espécie humana, caracterizada como homo sapiens.

E assim, o homem primitivo começa a construir ludicamente sua história, os atos religiosos celebrados com o objetivo de assegurar a tranquilidade do mundo, já eram realizados dentro de um espírito de jogo.

\subsection{O lúdico na antiguidade e na Idade Média}

A civilização Egípcia foi a primeira a ser fornada na antiguidade, tendo como característica o aspecto místico. Os Egípcios valorizavam o jogo como esporte e diversão, as lutas e a natação eram os esportes mais populares, onde a competição era um fator indispensável. Os jogos mais apreciados eram a dama e o xadrez e as crianças também tinham seus jogos e suas brincadeiras conhecidas, como bolas de couro e bonecas.

Os Gregos se destacaram pelo amor ao esporte, foi na Grécia que surgiram os jogos Olímpicos. O esporte era realizado em homenagem aos deuses e os mais famosos aconteciam a cada quatro anos.

Platão (427-348 a.C.) defendia a importância dos jogos educativos e dos esportes físicos para o desenvolvimento integral da criança. Segundo Almeida (2003, p. 15), Platão dava ao esporte, tão difundido na época, “[ [...] valor educativo, 
moral, colocando-o em pé de igualdade com a cultura e em estreita colaboração com ela na formação do caráter e da personalidade."

Os Gregos também utilizavam, a música, a dança e a ginástica como formas lúdicas de manifestação na formação dos jovens.

De acordo com Gallo (2007, p. 25-26):

[...] a Grécia Antiga representou, certamente, uma das civilizações que contou com a maior presença do universo do jogo em sua cultura. O homem livre não era obrigado a trabalhar para "ganhar a vida" e seu tempo era dedicado às atividades consideradas mais "nobres e edificantes", de caráter educativo. O homem tinha que se educar e aprender certas coisas - variáveis de acordo com o interesse de cada pessoa - não em nome do trabalho, mas em nome dessas próprias coisas. A importância do jogo em todas as esferas do desenvolvimento da cultura antiga grega acabou por repercutir e influenciar diversas outras culturas até a Idade Média, como podemos observar de maneira incisiva no Império Romano [...].

Com isso, segundo Modesto (2009, p. 18) "O ato de jogar bola foi um dos jogos atribuídos ao modo de vida dos romanos, pois após a invasão bárbara, este estilo foi adotado. Através de jogos, os romanos aprendiam a manter relações profundas entre si e a viverem em conjunto, pois o jogo não é uma atividade isolada e no decorrer desta atividade procuravam o equilíbrio emocional".

O pão e circo eram instrumentos utilizados para animar e distrair a sociedade romana, onde "o governo interessado em obstruir a visão do cidadão quanto aos seus direitos, realizava espetáculos para que estes estivessem ocupados" (Modesto, 2009, p. 18).

Na Idade Média, a arte era uma das formas de expressão do contexto o qual se está inserido, nessa época a igreja detinha o poder onde o homem tinha um destino espiritual, devendo se preocupar apenas com a salvação. Na era medieval a arte representava as crianças e seu respectivo lugar na sociedade, estas eram tratadas com adultos em miniatura, pois como afirma Aries (1981, p. 32) "o artista da era medieval não fazia questão de representar este ser quanto sua existência social, pintava um adulto em miniatura, onde somente a estatura distinguia estes dois seres, adultos e crianças".

\subsection{O lúdico na Idade Moderna e Contemporânea}

Na sociedade Moderna o lúdico era uma especificidade infantil, no entanto o sentimento lúdico existia entre as crianças de maneira abafada, pois, os adultos rejeitavam a infância.

Mesmo sendo rejeitados pelos adultos, o jogo, parte integrante e essência do lúdico, era a base desta civilização e palco da vida, de acordo com Huizinga (2001, p. 23), “[...] era costume o homem comparar a vida a um palco, no qual cada homem desempenhava seu papel".

Nesse sentido, Almeida e Rodrigues (2015, p. 28) destacam que:

Devido ao modo de como era vista a criança na idade moderna, o lúdico era um pouco escondido pelo fato dos adultos de tal sociedade serem repreensivos, porém mesmo assim o lúdico era a base desse período. Perante a tal repreensão os jogos que surgiram nesse período vieram acompanhados de um forte espírito de competição, uma vez que, as crianças "imitavam" o adulto desde bem novos. É somente no final do século XVIII então que a criança passa a ter mais importância perante a sociedade.

As bonecas também foram bastante utilizadas por esta sociedade, entre as crianças e os adultos, o jogo era utilizado pelos adultos em cultos, ritos, sacrifícios e consagrações, sendo que muitos brinquedos surgidos nessa época vieram do espírito de competição por parte das crianças, pois seus desejos inadiáveis de imitar os adultos as faziam criar seu próprio brinquedo.

$\mathrm{Na}$ contemporaneidade as crianças começam a ganhar destaque, as meninas brincam de faz de conta, surgem os brinquedos industrializados, o brinquedo deixa de ser artesanal, perdendo assim a característica da criança que o constrói. 
Para Kunz (2001, p. 94), “a criança forma seu imaginário social, cultural, lúdico, através do seu pensar, agir e sentir [...]". O brinquedo agora tem que ter um controle maior por parte dos adultos. Segundo Weiss (1997, p. 21.) "quanto mais a industrialização avança, mais decididamente o brinquedo se subtrai ao controle da família".

\section{A Concepção do Brincar}

Na concepção de Jean Piaget, o brinquedo estimula a representação da realidade, ao representá-lo a criança viverá algo ou alguma situação remota e irreal naquele momento, irá reproduzir diálogos vivenciados e reproduzir a maneira como é tratada pelos adultos (Piaget, 1971). Para o mesmo, "quando brinca, a criança assimila o mundo a sua maneira sem compromisso com a realidade, pois, sua influência com o objeto não depende da natureza do objeto, mas da colocação que a criança the confere" (Piaget, 1971, p. 37).

O epistemólogo ainda diz que, "a atividade lúdica é o berço obrigatório das atividades intelectuais da criança. Estas não são apenas entretenimento, mas meios que contribuem e enriquecem o desenvolvimento intelectual" (Piaget, 1971, p. 38).

Já Vygotsky, define o brinquedo como algo que preenche as necessidades da criança, o que significa entendê-lo como algo que motiva para a ação, "o brincar é essencial para o desenvolvimento cognitivo da criança, pois os processos de simbolização e de representação a levam ao pensamento abstrato" (Vygotsky, 1994, p. 98).

Nas palavras de Kishimoto (2001, p. 13):

Tentar definir o jogo não é tarefa fácil. Quando se pronuncia a palavra jogo cada um pode entendê-la de modo diferente. Pode-se estar falando de jogos políticos, de adultos, de crianças, animais ou amarelinha, xadrez, adivinhas, contar estórias, brincar de "mamãe e filhinha", futebol, dominó, quebra-cabeça, construir barquinho, brincar na areia e uma infinidade de outros. Tais jogos, embora recebam a mesma denominação, têm suas especificidades.

Na concepção de Wallon (2007, p. 36), "toda atividade da criança é lúdica, no sentido que se exerce por si mesma antes de poder integrar-se em um projeto de ação mais extensivo que a subordine e a transforme em um meio específico". Para Winnicott (1975, p. 80), "a brincadeira se sustenta a partir de uma fantasia que se oculta dentro de si; é tarefa do analista de crianças interpretar esta fantasia. É através do brincar que a criança manifesta sua criatividade”.

Brincar é coisa séria, também, por que na brincadeira não há trapaça, há sinceridade engajamento voluntário e doação. Brincando nos reequilibramos, reciclamos nossas emoções e nossa necessidade de conhecer e reinventar. E tudo isso desenvolvendo atenção, concentração e muitas habilidades. É brincando que a criança mergulha na vida, sentindo-a na dimensão de possibilidades. No espaço criado pelo brincar nessa aparente fantasia, acontece a expressão de uma realidade interior que pode estar bloqueada pela necessidade de ajustamento às expectativas sociais e familiares (Vygotsky, 1994, p. 67).

Segundo Machado (1995, p. 37), "brincar é a primeira forma de manifestação da cultura, é no brincar que a criança lida com sua realidade interior e sua tradução livre da realidade exterior". De acordo com Nhary (2006, p. 15), "as atividades lúdicas são fundamentais no desenvolvimento do sujeito que possua ou não algum tipo de limitação. No decorrer das atividades lúdicas todos são tidos como capacitados de realizar a atividade coletivamente dentro das suas habilidades físicas, intelectuais, sociais".

As atividades lúdicas favorecem o envolvimento dos alunos nas atividades escolares facilitando os avanços no seu processo de aprendizagem como também no seu desenvolvimento intelectual e motor (Oliveira, 2003). Assim, os alunos com deficiências são envolvidos pelo lúdico, interagindo com os demais e desenvolvendo suas habilidades e potencialidades de maneira prazerosa. 
O aprendizado deve acontecer dentro de um ambiente que seja agradável e atrativo aos aprendizes, além de respeitar os diferentes níveis de raciocínio e as habilidades que são próprias de cada etapa do desenvolvimento humano. Com a utilização dos jogos o professor pode propiciar aos alunos a vivência em equipe, desenvolver a criatividade e a imaginação, além de proporcionar a prática de exercícios de relacionamento social. Mas, para isso ocorrer, deve estar convencido de que o jogo é um instrumento cognitivo e afetivamente significativo e que pode trazer enriquecimento as atividades pedagógicas. (Oliveira, 2003, pp. 123-124).

Por meio do brincar a criança conquista a autoestima, a autonomia e a criatividade, que são elementos essenciais para a construção do conhecimento e a inclusão de alunos com deficiências, no ambiente escolar.

\section{O Lúdico nos Processos de Aprendizagem e Desenvolvimento}

De acordo com Barnard e Erickson (1996, p. 47), "ao entrar na escola, a criança passa a ter contato com diferentes culturas, estilos e modos de vida, para alguns é o momento esperado e desejado, para outros é fonte de grande tensão, pois encontra-se em um mundo cheio de regras, permissões e proibições, diferente do mundo que conhece”.

Segundo Valle (2008, p. 10):

Ludicidade é envolver-se numa atividade, utilizando objetos, em geral brinquedos, que trazem prazer à criança. Neste contexto, o papel do professor seria ajudar o aluno a aprender novos conteúdos com o uso de estratégias e atividades prazerosas. O brincar é uma ação que está presente em todos os períodos do desenvolvimento. Os objetos que despertam o interesse lúdico mudam dependendo da fase em que o ser humano se encontra.

Este cenário pode levar a criança a ter reações como tristeza, ansiedade, insegurança e medo, afastando o prazer de aprender, e muitas vezes colaborar para o fracasso escolar. Nesse sentido, o professor tem o papel fundamental de resgatar e proporcionar o prazer de aprender em seus educandos, formando um elo de afeto, respeito e afetividade entre professor e aluno (Mello, 1986).

Quando o ambiente educativo é acolhedor, a criança terá melhores condições de controlar seus impulsos agressivos e amorosos, podendo assim, desenvolver sua personalidade.

As atividades lúdicas não são apenas momentos divertidos ou simples passatempos. São muito mais que isso. São momentos de descoberta, de construção e compreensão de si; estímulos à autonomia e à expressão pessoal, momentos de expansão em que as contrações que se cronificaram começam a ceder, e a pulsação que marca a presença da vida viva vai sendo retomada. (Pereira, 2005, p. 93).

Dessa forma, “A brincadeira é um excelente recurso pedagógico para o aprendizado na formação da personalidade do ser humano. Do ponto de vista criativo, a prática de brincar está focalizado na busca do "eu", manifestando a criatividade, a imaginação e o desenvolvimento das habilidades do indivíduo (Fonseca, Julião, Silva \& Santos, 2020, p. 3).

Logo, é importante frisar que:

Brincar é uma necessidade básica assim como é a nutrição, a saúde, a habitação e a educação, brincar ajuda a criança no seu desenvolvimento físico, afetivo, intelectual e social, pois, através das atividades lúdicas, a criança forma conceitos, relaciona ideias, estabelece relações lógicas, desenvolve a expressão oral e corporal, reforça habilidades sociais, reduz a agressividade, integra-se na sociedade e constrói seu próprio conhecimento. (Ferreira, 2007, p. 124).

Nas palavras do poeta Manoel de Barros, as aprendizagens mais importantes são coloridas pelas tintas dos encontros que nos tocam pelo viés do sensível. E isso, nenhum currículo pode abarcar. Somente um olhar que vê, revê e "transvê" o mundo, pode trabalhar com essas singelezas (Barros, 2008). 


\section{Considerações Finais}

A brincadeira, além do divertimento traz outros benefícios fundamentais como: integração, socialização, desenvolvimento das habilidades motoras, do pensamento, dos reflexos, o respeito as regras do grupo, vivacidade, fantasia, e desenvolvimento dos aspectos psicológicos da criança. As brincadeiras, os jogos, os brinquedos, estimulam a curiosidade, a iniciativa e autoconfiança no/a aluno/a, proporcionando aprendizagem, colaborando com o desenvolvimento da linguagem do/a educando/a.

Dessa forma, ressaltamos que as atividades lúdicas devem ser valorizadas e divulgadas em todas as escolas como instrumento facilitador e construtor de conhecimentos dentro do processo de inclusão de alunos/as especiais. Todavia, cabe aos educadores/as considerar o brincar como uma prática cotidiana e enriquecedora de sua dinâmica metodológica, em sala de aula, para que ocorra o desenvolvimento do/a aluno/a da Educação Especial em todas as suas potencialidades.

Além disso, o brincar contribui para que o/a aluno/a com necessidades especiais desenvolva suas habilidades máximas e esteja inserido no meio social que é a escola, contribuindo assim para a sua formação como sujeito, pois ao estar em contado com outras crianças eles estão se socializando, interagindo e usufruindo de um direito que é comum a todos/as.

Não existe atividade mais completa para a criança do que o brincar, pois, as crianças começam a estudar brincando, assimilando conhecimentos sem perceber. Segundo alguns estudiosos a brincadeira educativa pode assumir muitas formas, então cabe a nós educadores/as modificar a brincadeira espontânea das crianças para que ela adquira um valor pedagógico, mas sem perder o aspecto lúdico.

Portanto, brincar e jogar são recursos riquíssimos no desenvolvimento de habilidades, se tornando estratégias de ensino possíveis de atingir diferentes objetivos e áreas do conhecimento, se os currículos não contemplam as aprendizagens através do lúdico, cabe ao/à professor/a buscar sua criança interior para que lhe aponte caminhos.

Como proposta para um trabalho futuro pretende-se fazer uma fundamentar uma revisão que articula os fundamentos das tecnologias educacionais em contribuição ao processo de ensino e aprendizagem na inclusão escolar.

\section{Referências}

Almeida, P. N. de. (2003). Educação lúdica. Técnicas e jogos pedagógicos. (11a. ed.). Loyola.

Almeida, E. R. (2014). O brincar na educação infantil das escolas de Piritiba/BA: o olhar docente. Universidade de Brasília.

Almeida, I. N. S., \& Rodrigues, L. A. (2015). O lúdico como recurso didático-pedagógico no desenvolvi mento da criança na educação infantil. Revista Humanidades e Inovação, Palmas.

Barnard, K., \& Erickison, M. (1996). Como educar crianças com problemas de desenvolvimento. Globo.

Barros, M. (2008). Só dez por cento é mentira. Documentário desbiográfico. Direção: Pedro Cezar. Brasil.

Brasil. Constituição (1988). Constituição da República Federativa do Brasil. Centro Gráfico.

Brasil. Ministério da Educação. (1996). Lei de Diretrizes e Bases. Lei no 9.394. 1996.

Brasil. Ministério da Educação. (2001). Diretrizes Nacionais para a Educação Especial na Educação Básica. Resolução CNE/CEB nº 2, de 11 de setembro de 2001 .

Brougère, G. (1997). Brinquedo e cultura. Cortez.

Dias, M. M. (2015). A brincadeira como recurso auxiliar ao desenvolvimento, aprendizagem e inclusão da criança com necessidades educacionais especiais. Brasília: Universidade Aberta do Brasil.

Ferreira, L. (2007). Educação, inclusão e ludicidade: uma análise histórica e filosófica. Enciclopédia Biosfera.

Fonseca, S. M., Julião, M. A. S., Silva, A. G. F., \& Santos, M. A. S. (2020). Educação Especial: A Ludicidade no processo ensino-aprendizado. Anais Educação e Formação Continuada na Contemporaneidade. Natal, RN, Brasil. 
Gallo, S. N. (2007). Jogo como elemento da cultura: aspectos contemporâneos e as modificações na experiência do jogar. São Paulo: Programa de Pósgraduação em Comunicação e Semiótica da Puc-SP.

Gil, A. C. (2002). Como elaborar projetos de pesquisa. Atlas.

Gil, M. (2017). A Legislação Federal Brasileira e a Educação de Alunos com Deficiências. https://diversa.org.br/artigos/a-legislacao-federal-brasileira-e-aeducacao-de-alunos-com-deficiencia/

Huizinga, J. (2001). Homo ludens: o jogo como elemento da cultura. Perspectiva.

Kishimoto, T. (2001). Jogo, brinquedo, brincadeira e educação. Cortez.

Kunz, E. (2001). Didática da educação física. Unijuí.

Machado, M. L. A. (1995). Educação Infantil e Sócio Interacionismo. In Oliveira, Z. M. R. (org.) Educação Infantil: muitos olhares. São Paulo: Cortez.

Mello, G. N. (1986). Educação escolar: paixão pensamento e prática. Cortez.

Minayo, M. C. S. (2002). Pesquisa social: Teoria, método e criatividade. Editora Vozes.

Nhary, T. M. C. (2006). O que está no jogo em jogo. Cultura, imagens e simbolismos na formação de professores. Dissertação de Mestrado em Educação, UFF, Niterói, Brasil.

Oliveira, L. M. G. (2003). Educação Especial e Tecnologias computacionais: Jogos que auxiliam as crianças. Anais Encontro Paranaense de Psicopedagogia, p. 123-129. http://www.educadores.diaadia.pr.gov.br/arquivos/File/2010/artigos_teses/jogos_de_computador.pdf

Pereira, L. H. P. (2005). Bioexpressão: a caminho de uma educação lúdica para a formação de educadores. Universidade Federal da Bahia. Faculdade de Educação, Salvador, Bahia.

Piaget, L. E. (1971). A formação do símbolo na criança. Zahar.

Roloff, E. M. (2010). A importância do lúdico em sala de aula. X Semana de Letras, 70, 1-9.

Sant'Anna, A., \& Nascimento, P. R. (2011). A história do lúdico na educação, Revista Eletrônica de Educação Matemática, 6(2), 19-36. https://doi.org/10.5007/1981-1322.2011v6n2p19

Silva, V. S. D. (2020). O lúdico como recurso metodológico na inclusão de alunos com deficiência intelectual no Ensino Fundamental. Revista Educação Pública, 20(20). https://educacaopublica.cecierj.edu.br/artigos/20/20/o-ludico-como-recurso-metodologico-na-inclusao-de-alunos-com-deficiencia-intelectualno-ensino-fundamental

Soares, E. M. (2010). A ludicidade no processo de inclusão de alunos especiais no ambiente educacional. Universidade do Estado do Rio de Janeiro, Faculdade de Formação de Professores. http://www.ffp.uerj.br/arquivos/dedu/monografias/EMS.2.2010.pdf

Unesco (1994). The Salamanca statement and framework for action on special needs education, adopted by the World Conference on Special Needs Education: access and quality, Salamanca, 7-10 June 1994 / Necessidades Educativas Especiais: Declaração de Salamanca sobre princípios, política e prática na área das necessidades educativas especiais. IIE. Inovação, separata.

Valle, T. G. M. (2008). Práticas educativas: criatividade, ludicidade e jogos. In Valle, T. G. M., \& Capellini, V. L. M. F. Práticas em educação especial e inclusiva na área da deficiência mental. Bauru. https://www.revistaacademicaonline.com/products/o-brincar-e-coisa-seria-na-educacao-inclusiva/

Wallon, H. (2007). Do ato ao pensamento. Edições.

Weiss, M. L. L. (1997). Psicopedagogia Clínica-Uma visão diagnóstica dos problemas de aprendizagem escolar. DP\&A.

Winnicott, D. W. (1975). Pensando sobre crianças. Arte Médicas.

Zopelari, L. F. P. (2010). A Influência do Lúdico para o desenvolvimento da aprendizagem de crianças de 1 a 3 anos. 